\title{
Stages in the Life History of Calanus finmarchicus (Gunnerus), Experimentally Reared by Mr. L. R. Crawshay in the Plymouth Laboratory.
}

\author{
By \\ Marie V. Lebour, M.Sc., \\ Assistant Lecturer in Zoology, Leeds University. \\ Temporary Naturalist in the Plymouth Laboratory.
}

With Plates 1 to 5 in the Text.

[The stages in the development of Calanus finmarchicus described and figured by Miss Lebour in the present paper were taken from culture jars given into my charge by Mr. L. R. Crawshay, when he left the Laboratory to undertake military duties in connection with the war. In one jar at that time the first copepodid stage, from eggs laid in the jar, had just been reached, and the technical details for the successful rearing of the animals had been mastered. The experiments had been conducted with great care, and all possible precautions had been taken to prevent contamination. Subsequently the experiments were repeated up to a certain point by myself and some additional stages obtained to complete the series.

The cultures were made in 2-litre glass beakers, containing " outside" sea-water filtered through a Berkefeld filter. In order to secure an even temperature the beakers stood in the circulating water of the Laboratory tanks, and a pure culture of the diatom Nitzschia closterium was used as food.-E. J. Allen.]

ALL the 5 copepodid stages (the 6th being the fully formed copepod) and 5 out of the 6 nauplius stages were found. Unfortunately the 6 th nauplius stage was missed and could not be found in the material, but it is described and well figured by Grobben (1903), and his figures and description show that it is very like the same stage of Pseudocalanus and Paracalanus described by Oberg (1906). The latter author's descriptions agree very closely with all the corresponding stages of Calanus finmarchicus, the size in all cases being the chief difference. In the very 
young nauplius stage the feelers differ in being long and thin in Calanus finmarchicus and short and hook-like in Pseudocalanus elongatus.

Nauplius Stage III is much the commonest stage and occurred all the time the material was being examined. The animal probably stays some time in this stage.

The number of bristles on the antennules of the nauplius is a sure guide to the stage, as they are constant and very easily seen. They also agree exactly in number with similar stages in Pseudocalanus and Paracalanus.

The colouring was much the same throughout all the stages, although not so marked in the early nauplius. The first nauplius stage has pigment present only in the region of the alimentary canal, where a few orange and red spots occur, and the tips of the appendages are a light orange. Later on the colouring is more marked. In the first copepodid stages and after the antennules are beautifully spotted with dark red, the bristles being red, and the furcal bristles are red merging into orange; the tips of the antennæ and mandibles are red, and the distal portions of all the appendages as far as the maxillipeds and also the hind end of the body are yellow. This colouring appears in all the copepodid stages with slight variations.

Grobben's descriptions agree well with the present material. Those stages which he figures are probably I, III, IV or V, and VI, also the first copepodid stage.

\section{THE NAUPLIUS.}

Stage I (Plate 1, Fig. 1). Only one specimen. This is very like Grobben's figure of the early nauplius, but he figures only 2 bristles on the antennule where the present specimen has 3. It appears to be an earlier stage than any of Oberg's. His Stage I of Pseudocalanus agrees with Stage II of the present species. His Stages III-V agree with the corresponding stages of Calanus as described in the present paper. Length of body $0 \cdot 21 \mathrm{~mm}$, oval, slightly more pointed posteriorly than anteriorly, faintly pink with orange tips to the appendages. Eye dark red. A pair of thin feelers at the hind end of the body.

Appendage I. Antennule (Plate 2, Fig. 1). The end segment divided off, the other 2 merely indicated. A small bristle just behind the end segment, the latter bearing 3 bristles.

Appendage II. Antenna (Plate 2, Fig. 6).

Coxopodite with a large thorn-like masticatory process.

Basipodite with 2 roundish prominences, the proximal portion with 2 small bristles. 

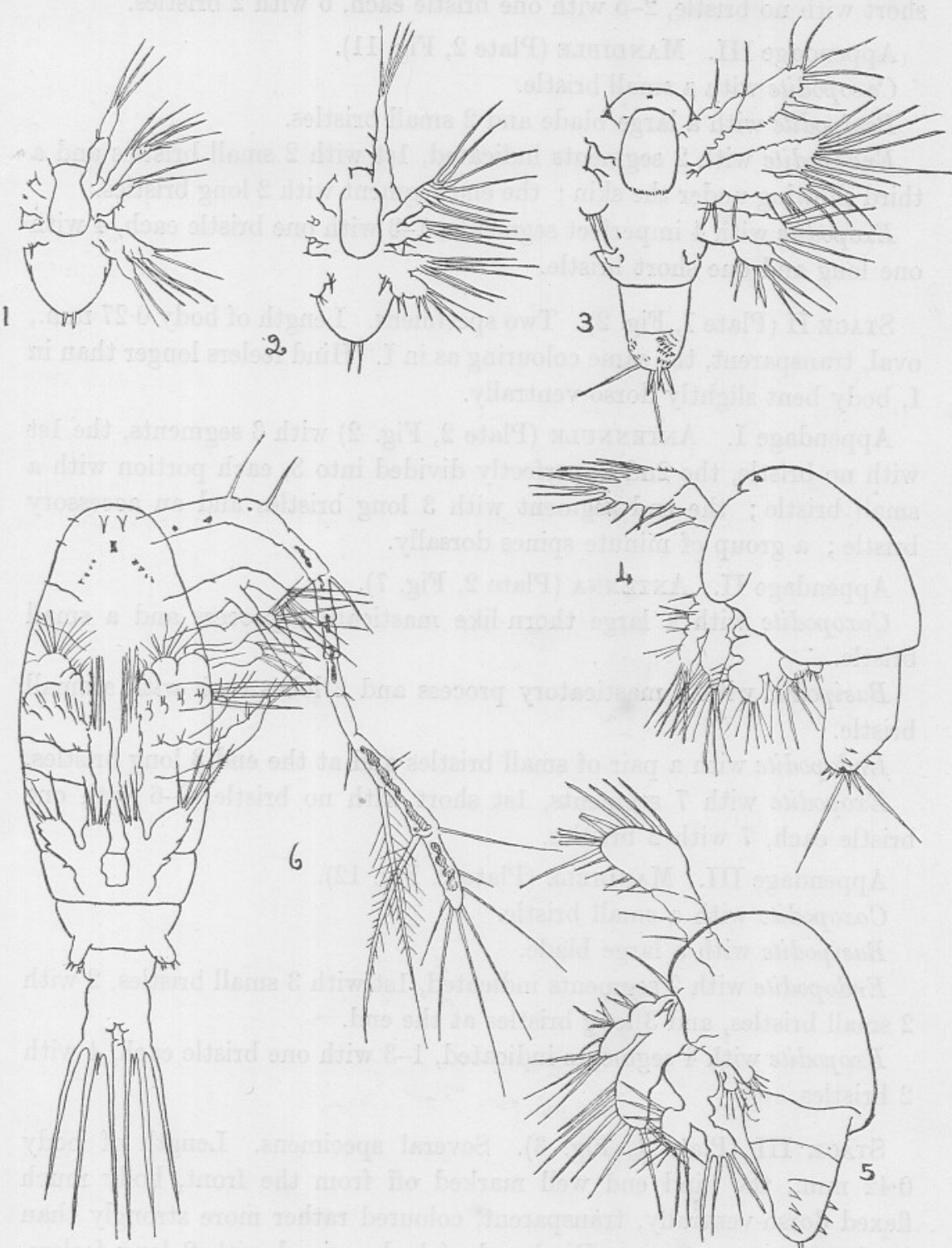

M.V.L, DEL.
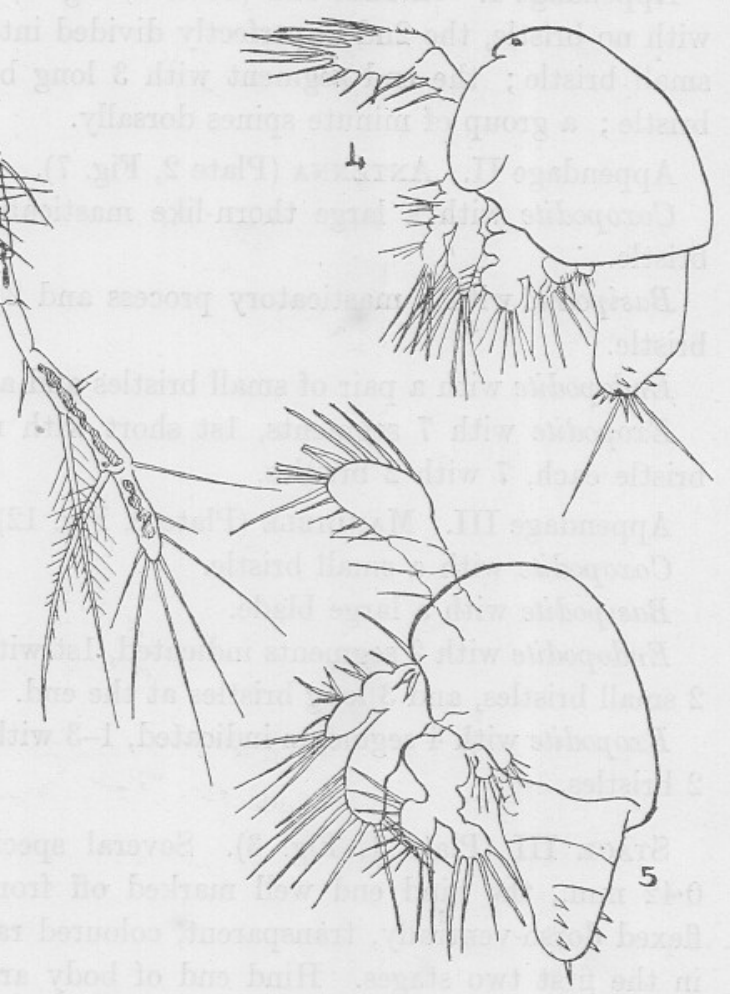
Endopodite with 2 long bristles at the end.

Exopodite with 6 segments, the 7 th showing under the skin, 1st segment short with no bristle, $2-5$ with one bristle each, 6 with 2 bristles.

Appendage III. Mandible (Plate 2, Fig. 11).

Coxopodite with a small bristle.

Basipodite with a large blade and 2 small bristles.

Endopodite with 2 segments indicated, 1st with 2 small bristles and a third showing under the skin; the end segment with 2 long bristles.

Exopodite with 4 imperfect segments, 1-3 with one bristle each, 4 with one long and one short bristle.

Stage II (Plate 1, Fig. 2). Two specimens. Length of body $0.27 \mathrm{~mm}$., oval, transparent, the same colouring as in I. Hind feelers longer than in I, body bent slightly dorso-ventrally.

Appendage I. Antennule (Plate 2, Fig. 2) with 3 segments, the 1st with no bristle, the 2 nd imperfectly divided into 3 , each portion with a small bristle; the end segment with 3 long bristles and an accessory bristle ; a group of minute spines dorsally.

Appendage II. Antenna (Plate 2, Fig. 7).

Coxopodite with a large thorn-like masticatory process and a small bristle.

Basipodite with a masticatory process and 2 lobes each with a small bristle.

Endopodite with a pair of small bristles and at the end 3 long bristles.

Exopodite with 7 segments, 1st short with no bristle, 2-6 with one bristle each, 7 with 2 bristles.

Appendage III. Mandible (Plate 2, Fig. 12).

Coxopodite with a small bristle.

Basipodite with a large blade.

Endopodite with 2 segments indicated, 1st with 3 small bristles, 2 with 2 small bristles, and 3 long bristles at the end.

Exopodite with 4 segments indicated, 1-3 with one bristle each, 4 with 2 bristles.

Stage III (Plate 1, Fig. 3). Several specimens. Length of body $0.42 \mathrm{~mm}$., the hind end well marked off from the front, body much flexed dorso-ventrally, transparent, coloured rather more strongly than in the first two stages. Hind end of body armed with 2 long feelers, one dorsal and one ventral, a pair of lateral and a pair of posterior hooks. Near the hooks are 3 rows of very short, sharp spines and the same sort of spines surround the bases of the hooks. Besides the 3 pairs of appendages there is a slight indication of a 4 th (maxillule). 
M. V. Lebour, Calanus finmarchicus.

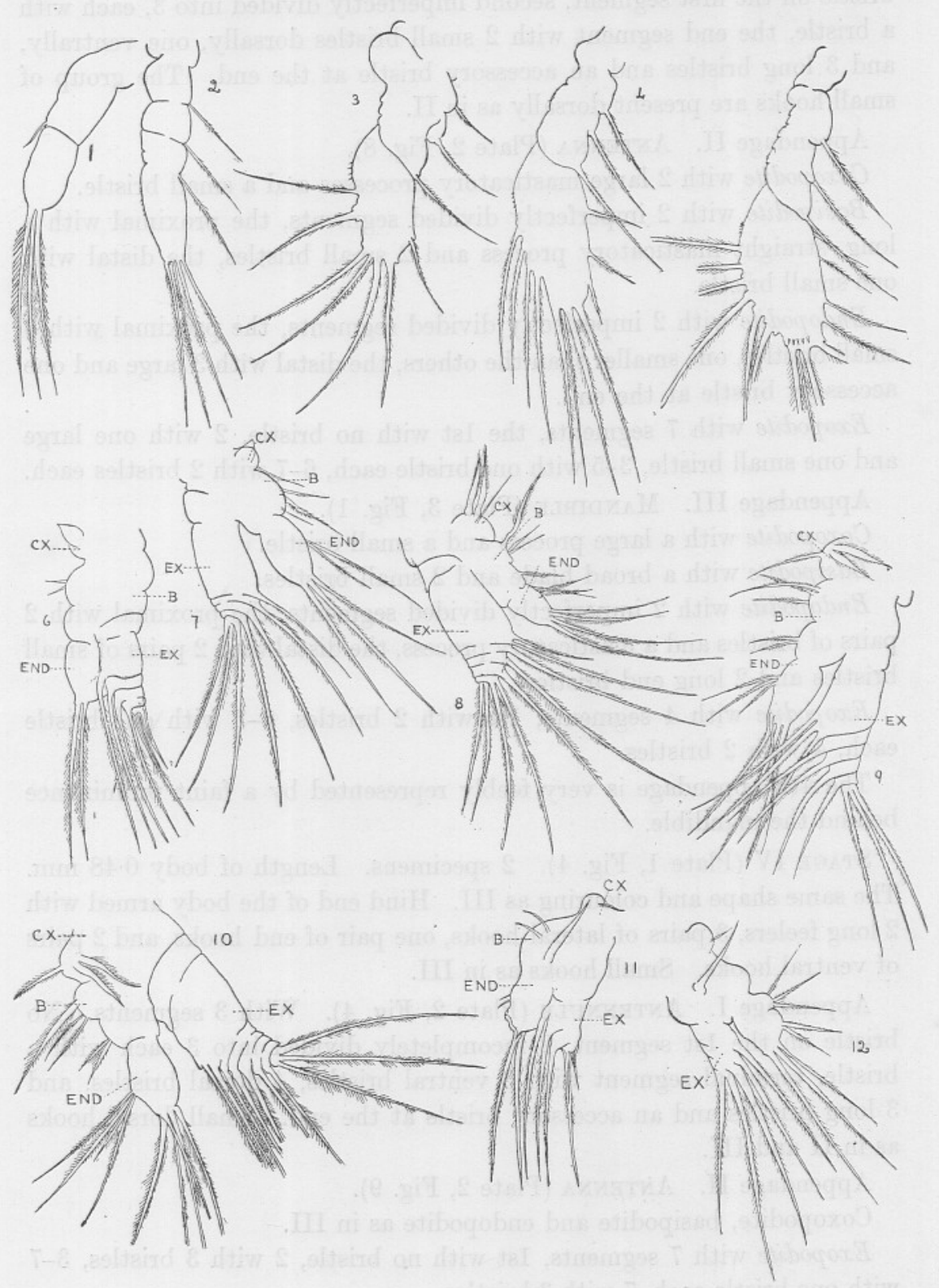

M. V.L, DEL. 
Appendage I. Antennule (Plate 2, Fig. 3). With 3 segments, no bristle on the first segment, second imperfectly divided into 3 , each with a bristle, the end segment with 2 small bristles dorsally, one ventrally, and 3 long bristles and an accessory bristle at the end. The group of small hooks are present dorsally as in II.

Appendage II. Antenna (Plate 2, Fig. 8).

Coxopodite with 2 large masticatory processes and a small bristle.

Basipodite with 2 imperfectly divided segments, the proximal with a long, straight masticatory process and 2 small bristles, the distal with one small bristle.

Endopodite with 2 imperfectly divided segments, the proximal with 3 small bristles, one smaller than the others, the distal with 3 large and one accessory bristle at the end.

Exopodite with 7 segments, the 1st with no bristle, 2 with one large and one small bristle, $3-5$ with one bristle each, $6-7$ with 2 bristles each.

Appendage III. Mandible (Plate 3, Fig. 1).

Coxopodite with a large process and a small bristle.

Basipodite with a broad blade and 2 small bristles.

Endopodite with 2 imperfectly divided segments, the proximal with 2 pairs of bristles and a masticatory process, the distal with 2 pairs of small bristles and 2 long end bristles.

Exopodite with 4 segments, 1st with 2 bristles, 2-3 with one bristle each, 4 with 2 bristles.

The 4 th appendage is very feebly represented by a faint prominence behind the mandible.

Stage IV (Plate 1, Fig. 4). 2 specimens. Length of body 0.48 mm. The same shape and colouring as III. Hind end of the body armed with 2 long feelers, 3 pairs of lateral hooks, one pair of end hooks, and 2 pairs of ventral hooks. Small hooks as in III.

Appendage I. Antennule (Plate 2, Fig. 4). With 3 segments. No bristle on the 1st segment, 2 incompletely divided into 3 each with a bristle, terminal segment with 3 ventral bristles, 4 dorsal bristles, and 3 long bristles and an accessory bristle at the end. Small dorsal hooks as in II and III.

Appendage II. Antenna (Plate 2, Fig. 9).

Coxopodite, basipodite and endopodite as in III.

Exopodite with 7 segments, 1st with no bristle, 2 with 3 bristles, 3-7 with one bristle each, 7 with 3 bristles.

Appendage III. Mandible (Plate 3, Fig. 2).

Coxopodite with a well-developed toothed process like the adult but with fewer teeth. 
M. V. Lebour. Calanus finmarchicus.

Plate 3.

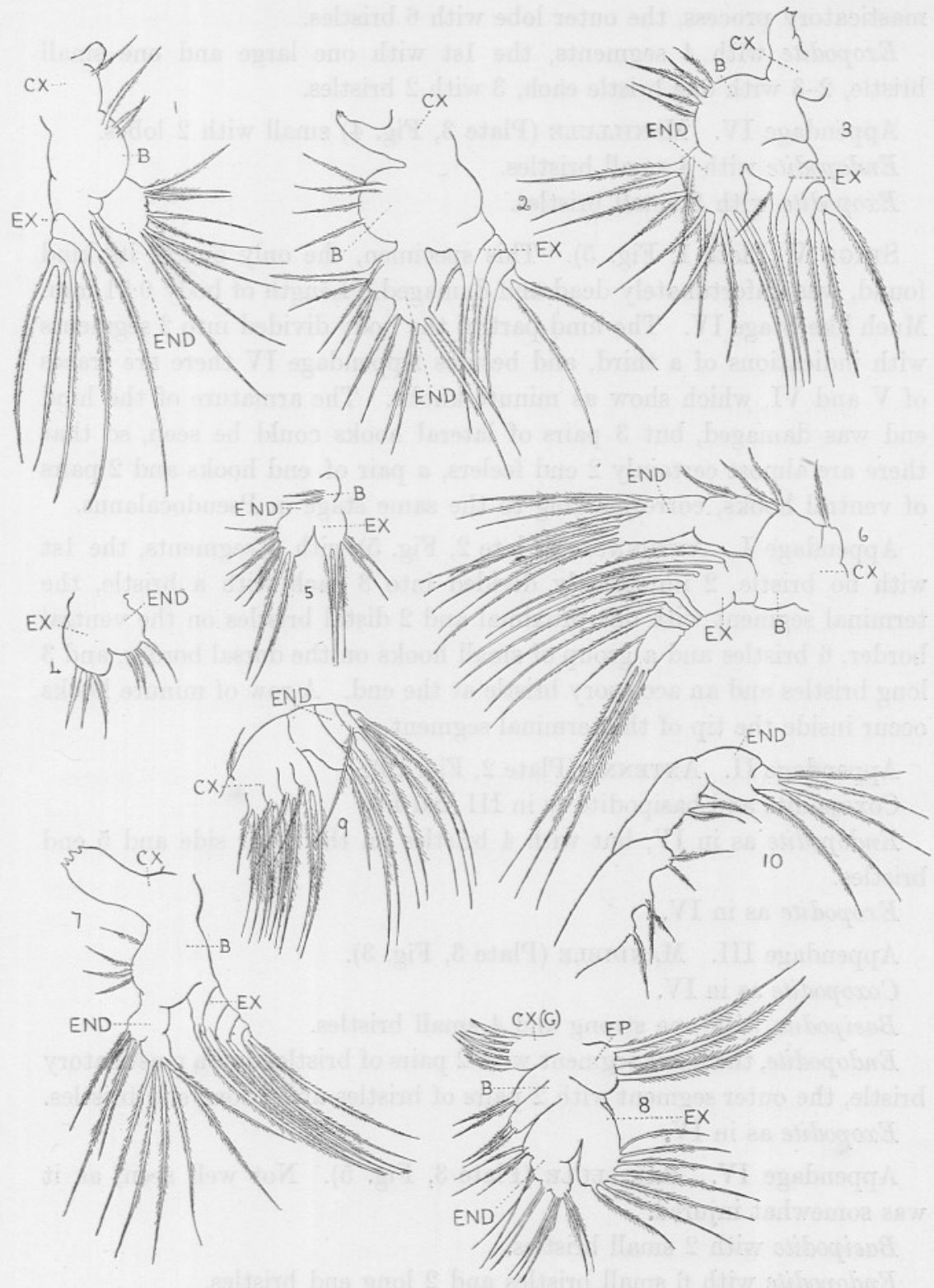

M. V.L, DEL. 
Basipodite with a large blade and 3 small bristles.

Endopodite with 2 lobes, the inner lobe with 4 bristles and a small masticatory process, the outer lobe with 6 bristles.

Exopodite with 4 segments, the 1st with one large and one small bristle, 2-3 with one bristle each, 3 with 2 bristles.

Appendage IV. Maxillule (Plate 3, Fig. 4) small with 2 lobes.

Endopodite with 4 small bristles.

Exopodite with 3 small bristles.

Stage V (Plate 1, Fig. 5). This specimen, the only one of its kind found, was unfortunately dead and damaged. Length of body $0.51 \mathrm{~mm}$. Much like Stage IV. The hind part of the body divided into 2 segments with indications of a third, and besides Appendage IV there are traces of $\mathrm{V}$ and VI, which show as minute knobs. The armature of the hind end was damaged, but 3 pairs of lateral hooks could be seen, so that there are almost certainly 2 end feelers, a pair of end hooks and 2 pairs of ventral hooks, corresponding to the same stage in Pseudocalanus.

Appendage I. Antennule (Plate 2, Fig. 5) with 3 segments, the 1st with no bristle, 2 imperfectly divided into 3 each with a bristle, the terminal segment with one proximal and 2 distal bristles on the ventral border, 6 bristles and a group of small hooks on the dorsal border, and 3 long bristles and an accessory bristle at the end. A row of minute hooks occur inside the tip of the terminal segment.

Appendage II. Antenna (Plate 2, Fig. 10).

Coxopodite and basipodite as in III and IV.

Endopodite as in IV, but with 4 bristles on the inner side and 5 end bristles.

Exopodite as in IV.

Appendage III. Mandible (Plate 3, Fig. 3).

Coxopodite as in IV.

Basipodite with one strong and 4 small bristles.

Endopodite, the inner segment with 2 pairs of bristles and a masticatory bristle, the outer segment with 2 pairs of bristles and 2 long end bristles.

Exopodite as in IV.

Appendage IV. Maxillule (Plate 3, Fig. 5). Not well seen, as it was somewhat injured.

Basipodite with 2 small bristles.

Endopodite with 6 small bristles and 2 long end bristles.

Exopodite with 2 short bristles and 3 long end bristles.

Stage VI. Not seen. Grobben gives a good figure of this stage, which is very like the description and figure of Pseudocalanus by Oberg. The 
rather long body is armed at the hind end with 4 pairs of lateral hooks, 2 feelers, 2 end hooks, and 2 pairs of ventral hooks. The maxillæ and maxillipeds are well developed and swimming feet I and II are present as bilobed structures.

This is the last nauplius stage.

\section{COPEPODID STAGES.}

There are 5 copepodid stages before the animal is fully formed. These were recognised by Gran (1902), who gives 6 stages, the last being the mature Calanus. All the 5 stages occurred and were taken from experimental jars started on March 30th, 1915. Nauplii first appeared between the 17th and 24th of April, and on May 19th Stage V was taken from the jar, having taken certainly less than two months to grow from the egg to this stage.

The species can be recognised from the first copepodid stage by the 2 long sensory bristles on the penultimate segments of the antennules. The rostral processes are distinct even in the first stage, which, according to Oberg, is not the case with Pseudocalanus, where they appear only in the second stage.

Stage I (Plate 1, Fig. 6, and Plate 4, Fig. 1). Length of body $0.80 \mathrm{~mm}$. Three free thoracic segments and urosome of one segment with an anterior constriction. In shape like the adult, but broader in comparison with its length. Caudal furca like the adult, but with 3 long bristles and one short bristle, besides a short inner bristle each side. The antennules are now long like the adult, and usually held out almost at right angles to the body. Colour pale yellow all round the edges of the body, antennules, antennæ, mandibles, part of maxillule, maxilliped, and caudal furca, the tips of all these appendages changing from yellow to red as the extremities are reached. Red pigment occurs all along the antennules, the 3 end segments being almost completely red, and dark red blotches run from the base to about the centre. Traces of red pigment are to be seen in the anterior part of the body. Eye dark red. Rostral processes present. There are 2 pairs of well-developed swimming feet and one rudimentary pair. All the other appendages are well developed.

Appendage I. Antennule 10 jointed, long, red sensory bristles, one on the antepenultimate and one on the penultimate segment.

Appendage II. Antenna (Plate 3, Fig. 6).

Coxopodite very small with one bristle.

Basipodite, the masticatory bristle has disappeared. 2 bristles present. 

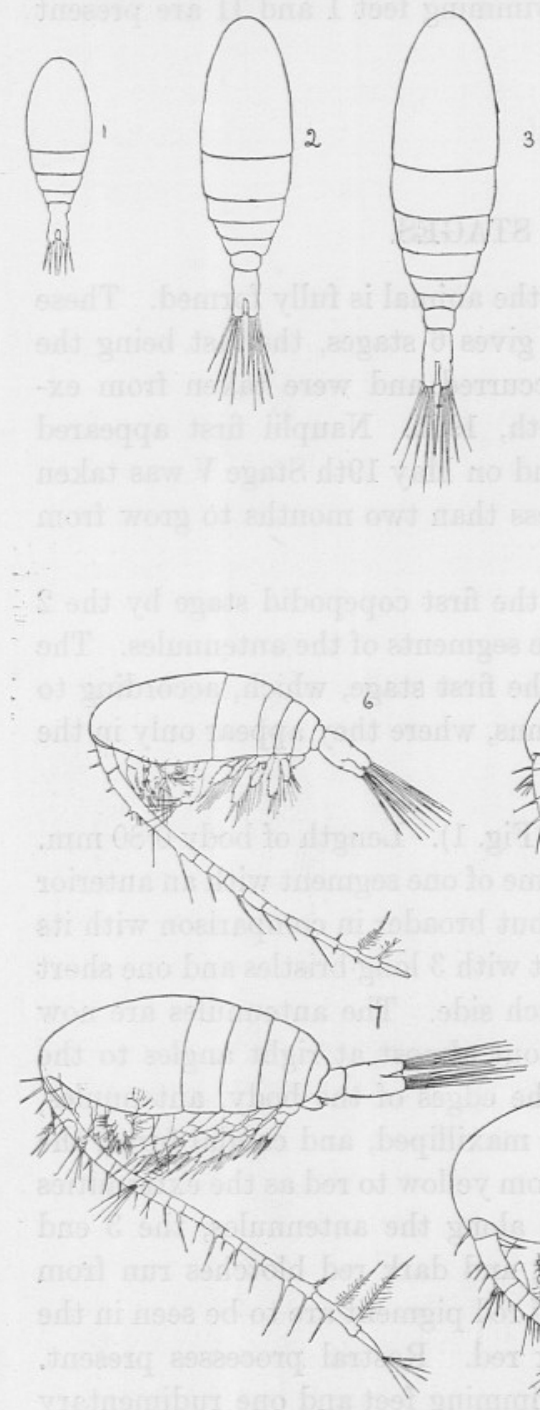

-10.
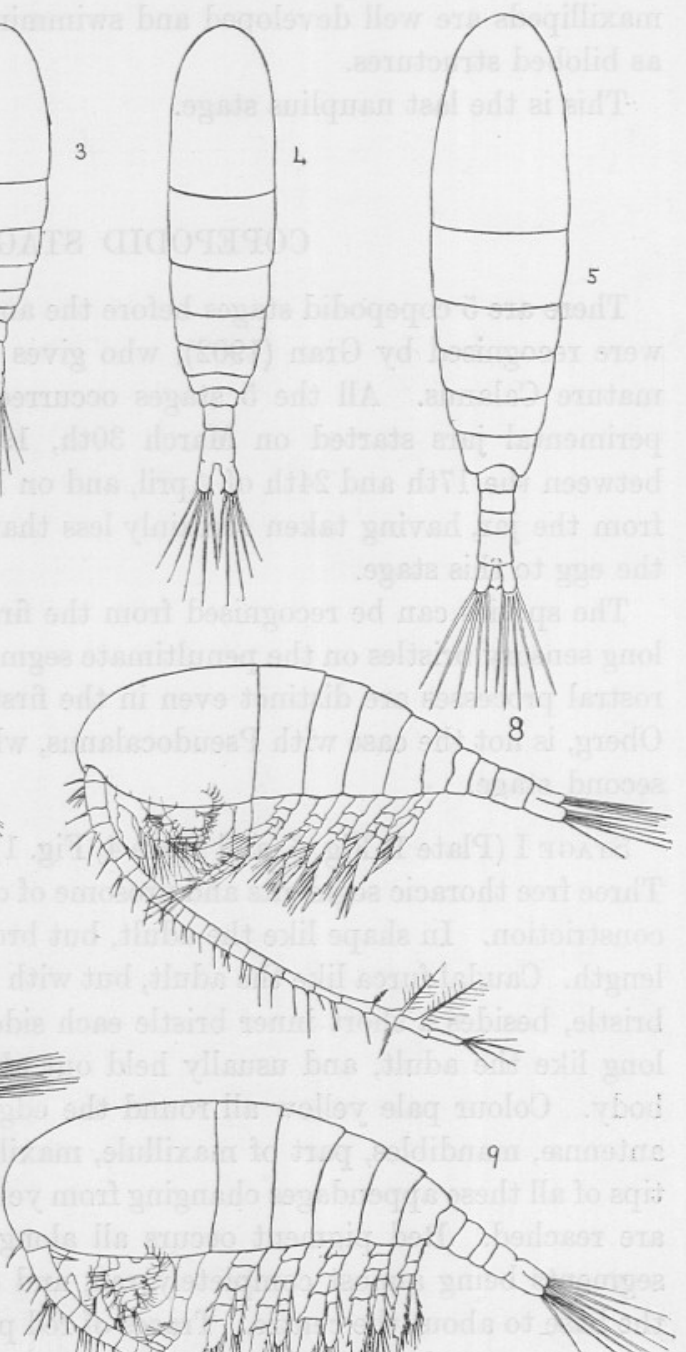

mo $19-4-11$

m. 4 M M M M thing

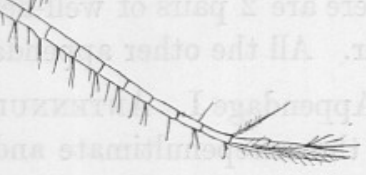

M.V.L. DEL, 

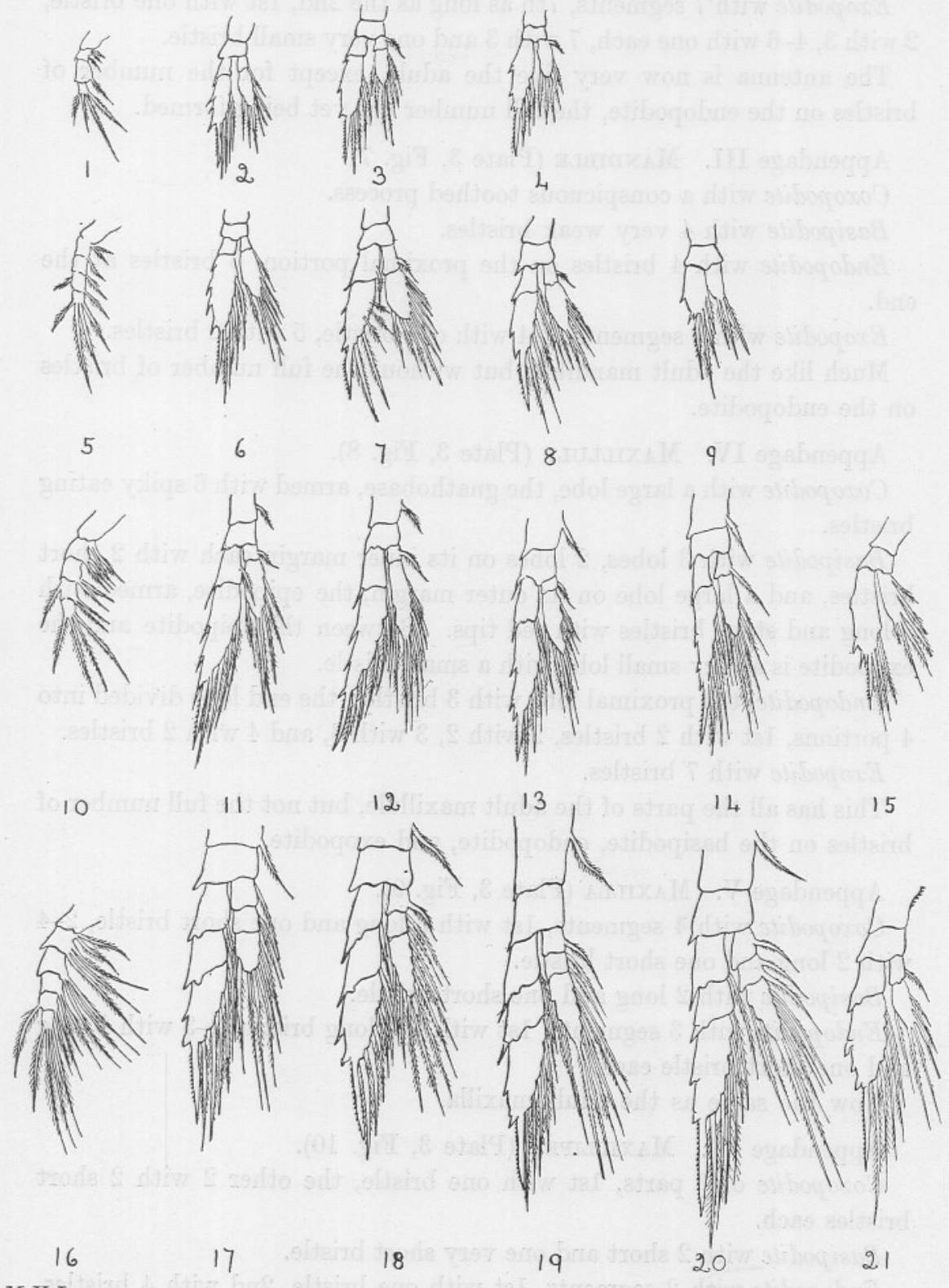

M.V.L. DEL。 
Endopodite with 2 segments, 1st with 2 bristles, 2 with 4 lateral bristles and 5 end bristles.

Exopodite with 7 segments, 7 th as long as the 2nd, 1st with one bristle, 2 with 3, 4-6 with one each, 7 with 3 and one very small bristle.

The antenna is now very like the adult, except for the number of bristles on the endopodite, the full number not yet being formed.

Appendage III. Mandible (Plate 3, Fig. 7).

Coxopodite with a conspicuous toothed process.

Basipodite with 4 very weak bristles.

Endopodite with 4 bristles on the proximal portion, 6 bristles at the end.

Exopodite with 5 segments, 1-4 with one bristle, 5 with 2 bristles.

Much like the adult mandible, but without the full number of bristles on the endopodite.

Appendage IV. Maxillule (Plate 3, Fig. 8).

Coxopodite with a large lobe, the gnathobase, armed with 6 spiky eating bristles.

Basipodite with 3 lobes, 2 lobes on its inner margin each with 2 short bristles, and a large lobe on its outer margin, the epipodite, armed with 3 long and stout bristles with red tips. Between the epipodite and the exopodite is a very small lobe with a small bristle.

Endopodite, the proximal lobe with 3 bristles, the end lobe divided into 4 portions, 1st with 2 bristles, 2 with 2,3 with 3 , and 4 with 2 bristles.

Exopodite with 7 bristles.

This has all the parts of the adult maxillule, but not the full number of bristles on the basipodite, endopodite, and exopodite.

Appendage V. Maxilla (Plate 3, Fig. 9).

Coxopodite with 4 segments, 1st with 3 long and one short bristle, 2-4 with 2 long and one short bristle.

Basipodite with 2 long and one short bristle.

Endopodite with 3 segments, 1st with one long bristle, 2-3 with 2 long and one short bristle each.

Now the same as the adult maxilla.

Appendage VI. Maxilliped (Plate 3, Fig. 10).

Coxopodite of 3 parts, 1st with one bristle, the other 2 with 2 short bristles each.

Basipodite with 2 short and one very short bristle.

Endopodite with 2 segments, 1st with one bristle, 2nd with 4 bristles.

Appendage VII. 1st Swimming Foot.

Coxopodite and basipodite with no bristles. 
Endopodite unsegmented, with 4 long bristles.

Exopodite unsegmented, with 4 thorns on the outer margin, a terminal blade, and 3 bristles inside.

Appendage VIII. 2ND SwImming Foot. Like the first, but with one more bristle on the inside of the endopodite. The exopodite has 4 thorns outside and a terminal bristle, with 3 bristles inside.

Appendage IX. 3RD Swrmming Foot with 2 lobes, each lobe with 2 hooks at the end.

Stage II (Plate 4, Figs. 2 and 6).

Length of body $1.20 \mathrm{~mm}$., 4 free thoracic segments, urosome of 2 segments. Caudal furca like the adult, with 5 bristles and a small lateral inner bristle. Colouring the same as I, but slightly lighter. 3 pairs of swimming feet and the rudiments of a 4 th pair.

Appendage I. Antennule with 12 segments, the last 7 the same as I.

Appendage II. Antenna the same as I.

Appendage III. Mandible the same as I.

Appendage IV. Maxillule the same as I, but with 7 bristles on the epipodite.

Appendage V. Maxilla the same as I.

Appendage VI. Maxilliped (Plate 5, Fig. 1).

Endopodite with a 3rd segment, 1st segment with one broad and 2 small bristles, other segments as in I.

Appendage VII. 1st Swimming Foot (Plate 5, Fig. 2).

Endopodite with 2 segments, no bristle on 1st segment, 2 with 2 long bristles on the outside, one terminal bristle, and 4 bristles inside.

Exopodite with 2 segments, a thorn on the outside of the first, 2 thorns on the outside of the 2nd, a terminal blade, and 4 long bristles inside.

Appendage VIII. 2ND Swrmmeng Foot (Plate 5, Fig. 3).

Endopodite with 2 segments, 1st with one bristle, 2 nd with 4 bristles inside, a terminal bristle, and 2 bristles outside.

Exopodite with 2 segments, 1st with a thorn, 2nd with 3 thorns outside, a terminal blade, and 4 bristles inside.

Appendage IX. 3RD Swrmmng Foot (Plate 5, Fig. 4).

Endopodite unsegmented, one proximal and 3 distal bristles inside, a terminal bristle, and one bristle outside.

Exopodite unsegmented, 3 thorns outside, a terminal blade, and 3 bristles inside.

Appendage X. 4тн Swimming Foot with 2 lobes each with 2 hooks. 
Stage III (Plate 4, Figs. 3 and 7). Like Stage II in colouring. Body more elongated. Length $1.20 \mathrm{~mm}$., 5 free thoracic segments. Urosome of 2 segments. All 5 swimming feet present, the 5th rudimentary.

Appendage I. Antennule with 16 segments, otherwise like II.

Appendage II. Antenna like I and II, but with 6 bristles on the inner part of the endopodite.

Appendage III. Mandible like I and II, but with 8 bristles at the end of the exopodite.

Appendage IV. Maxillule.

Coxopodite with the gnathobase bearing 8 bristles.

Basipodite like I and II, but with 3 bristles on the proximal lobe.

Endopodite like I and II, but with 4 bristles on the first lobe and 10 on the end lobe.

Appendage V. Maxilla like adult.

Appendage VI. Maxilliped (Plate 5, Fig. 5).

Endopodite of 4 segments, 1st with 3 bristles, 2 with one, 3 with one and a small outer bristle, 4 with 4 bristles at the end.

Appendage VII. 1sт Swimming Foot (Plate 5, Fig. 6).

Endopodite with 2 segments, distal segment with 4 bristles inside, 2 terminal bristles, and one bristle outside.

Exopodite with 2 segments, distal segment with 4 bristles inside, a terminal blade, and 4 thorns outside.

Appendage VIII. 2ND Swimming Foot (Plate 5, Fig. 7).

Endopodite with 2 segments, proximal segment with one bristle inside, distal segment with 5 bristles inside, 2 terminal bristles, and 2 bristles outside.

Exopodite with 2 segments, one bristle on the proximal segment inside and a thorn outside, 5 bristles on the distal segment inside, a terminal blade, and 3 thorns outside.

Appendage IX. 3RD Swimming Foot (Plate 5, Fig. 8).

Endopodite with 2 segments, one bristle on the proximal segment inside, distal segment with 3 bristles inside, 2 terminal bristles, and 2 bristles outside.

Exopodite with 2 segments, the proximal segment with one bristle inside and a thorn outside, the distal segment with 4 bristles inside, a terminal blade, and 2 thorns outside.

Appendage X. 4тн Swimming Foot (Plate 5, Fig. 9).

Endopodite unsegmented, with 3 bristles.

Exopodite unsegmented, with 3 bristles inside, a terminal blade, and 3 thorns outside. 
Appendage XI. 5тн Swimming Fоoт 2-lobed, each lobe with 2 hooks.

Stage IV (Plate 4, Figs. 4 and 8). Very like III. Thorax with 5 free segments each with a well-developed swimming foot. Urosome of 3 segments.

Appendage I. Antennule with 23 segments.

Appendage II. Antenna like I, but with 7 bristles on the inner lobe of the endopodite. Very like the adult.

Appendage III. Mandible like I-III.

Appendage IV. Maxillule like I-III, but the epipodite is larger with 9 bristles now like the adult, the 1st inner lobe of the basipodite has 3 bristles like the adult, endopodite with 5 bristles at the end.

Appendage V. Maxilla like the adult.

Appendage VI. Maxilliped (Plate 5, Fig. 10).

Endopodite of 4 segments, 1st with 4 bristles, 2 with 2, 3 with 2 inside and one outside, terminal segment with 4 bristles.

Appendage VII. 1st Swrmming Foot (Plate 5, Fig. 11). The proximal joint of the basipodite with an inside bristle.

Endopodite with 2 segments, the proximal segment with an inside bristle, the distal segment with 3 inside bristles, 2 terminal bristles, and one outside bristle.

Exopodite with 2 segments, the proximal segment with an inside bristle and an outside thorn, the distal segment with 4 bristles inside, a terminal blade, and 3 thorns outside.

Appendage VIII. 2ND Swimming Foot (Plate 5, Fig. 12).

The proximal segment of the basipodite with an inside bristle, the distal segment with an outside thorn.

Endopodite with 2 segments, the proximal segment with one bristle inside, the distal segment with 5 bristles inside, 2 terminal bristles, and 2 bristles outside.

Exopodite with 2 segments, the proximal segment with one bristle inside and a thorn outside, the distal segment with 5 bristles inside, a terminal blade, and 3 thorns outside.

Appendage IX. 3RD Swimming Foot (Plate 5, Fig. 13). The proximal segment of the basipodite with a bristle inside, the distal segment with a thorn outside.

Endopodite with 2 segments, the proximal segment with one bristle inside, the distal segment with 4 bristles inside, 2 terminal bristles, and 2 bristles outside. 
Exopodite with 2 segments, the proximal segment with a bristle inside and a thorn outside, the distal segment with 4 bristles inside, a terminal blade, and 3 thorns outside.

Appendage X. 4тн Swimming Fоот (Plate 5, Fig. 14). The proximal segment of the basipodite with an inside bristle, the distal segment with a thorn outside.

Endopodite with 2 segments, the proximal segment with one bristle inside, the distal segment with 3 bristles inside, 2 terminal bristles, and 2 bristles outside.

Exopodite with 2 segments, the proximal segment with an outside thorn, the distal segment with 4 bristles inside, a terminal blade, and 3 thorns outside.

Appendage XI. 5тн Swimming Foot (Plate 5, Fig. 15).

Endopodite unsegmented, with 6 bristles.

Exopodite unsegmented, with 3 bristles inside, a terminal blade, and 3 thorns outside.

StAGE V (Plate 4, Figs. 5 and 9). Body much longer, the full number of segments in the thorax and urosome. Antennules, antennæ, mandibles, maxillules, maxillæ, and swimming feet I to IV like the adult. The maxilliped has not yet the full number of bristles (Plate 5, Fig. 16). 1st segment with 5 bristles, 2 with 3,4 with 2 inside and one outside, terminal segment with 4 bristles. The swimming feet (Plate 5, Figs. 17-21) are all like the adult with the exception of the last, which, although having the full number of bristles, has only 2 segments to the endopodite and exopodite.

Stage VI is the fully developed copepod.

\section{LITERATURE.}

1902. GRAN, H. H.-Das Plankton des Norwegischen Nordmeeres. Report on Norwegian Fishery and Marine Investigations. Vol. II, 1902, No. 5 .

1881. Grobben, C.-Die Entwicklungsgeschichte von Cetochilus septentrionalis Goodsir. Arbeiten aus dem Zoologischen Institute der Universität Wien, etc. Vol. III, Part 3.

1906. Oberg, M.-Die Metamorphose der Plankton-Copepoden der Kieler Bucht. Wissenschaftliche Meeresuntersuchungen herausgegeben von der Kommission zur Wissenschaftlichen Untersuchung der deutschen meer in Kiel, etc. N.S. Vol. IX. Abt. Kiel.

1903. SARS, G. O.-An Account of the Crustacea of Norway. Vol. IV. Copepoda Calanoida.

The work on the Copepoda of the Danish Ingolf Expedition, Vol. III, Part 4, 1915, by Carl With, came to hand after the present paper was in print. 


\section{EXPLANATION OF FIGURES.}

Plate 1.-1. Nauplius Stage I. $\times 80$.
2. ,, , II. ,
3. , , III. ,
4. , , , IV. ,
5. Copepodid ,"

Plate 2.-1. 1st Appendage (Antennule) of Nauplius I.

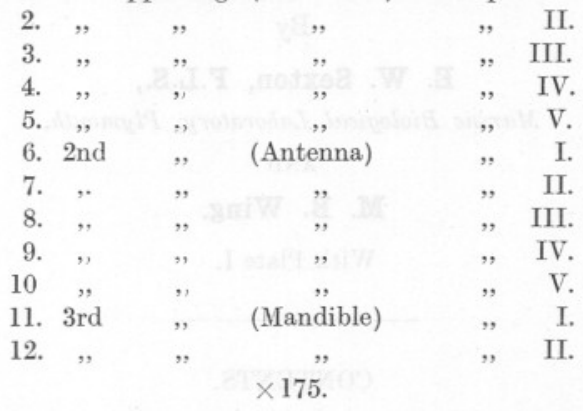

Plate 3.-1. 3rd Appendage (Mandible) of Nauplius III.
2.
3. ,
4. 4 th
,
5. ,
6. 2nd
7. 3rd
8. 4th
9. 5 th
10. 6 th

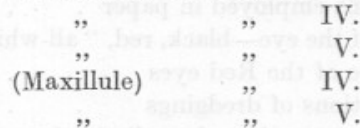
", ", " V.
, (Antenna) of Copepodid Stage I.
(Mandible)
," (Maxillule)
, (Maxilla)
, (Maxilliped)
$\times 175$.
CX Coxopodite.
B Basipodite.
EP Epipodite.
END Endopodite.
EX Exopodite.
G Gnathobase.

Plate 4.-1-5. Dorsal view of Copepodid Stages I-V.

6-9. Lateral view of Copepodid Stages II-V.

$\times 18$.

PLATE 5.-Distal portion of Maxilliped and Swimming Feet of Copepodid Stages II-V. $\times 26 \cdot 6$. 